\title{
Creation in the Age of Modern Science
}

\author{
William E. Carroll \\ University of Oxford \\ william.carroll@bfriars.ox.ac.uk
}

\begin{abstract}
In this paper William Carroll argues that the alleged conflict between creation and science has its origin in a mistaken comprehension of the meaning of "creation" and the extent of explication that natural sciences can offer. Carroll explains that creation, a metaphysical and theological notion, affirms that everything which exists depends on one single cause which is God. But, on the other side, the object of study of natural sciences is the realm of changing things. Whereas creation speaks to the cause of existence itself, evolutionary biology, cosmology and other natural sciences focus on phenomena subject to change. In contrast, creation should not be understood as the change from nothingness to something, but as a theological and metaphysical dependence in the order of being. This does not mean, however, that the theological and metaphysical approaches are incompatible with those of natural sciences.
\end{abstract}

Key words: creation, God, metaphysics, natural sciences.

Recibido: I7-OI-20I I. Aceptado: O8-I I-20I I.

Tópicos 42 (20I2), IO7-I24 


\section{Resumen}

En este artículo William Carroll argumenta que el presunto conflicto entre creación y ciencia tiene su origen en una errada comprensión del significado de "creación" y de los alcances explicativos de las ciencias naturales. Carroll explica que la creación, una noción metafísica y teológica, afirma que todo cuanto existe depende de una única causa que es Dios. Por su parte, el objeto de estudio de las ciencias naturales son las cosas cambiantes. Mientras la creación habla de la causa de la existencia en sí misma, la biología evolutiva, la cosmología y otras ciencias naturales, se concentran en fenómenos que están sujetos al cambio. En contraste, la creación no debe entenderse como un cambio desde la nada hacia algo, sino que es una cuestión metafísica y teológica. Esto no significa, sin embargo, que las aproximaciones teológica y metafísica sean incompatibles con las ciencias naturales.

Palabras clave: creación, Dios, metafísica, ciencias naturales.

The International Film Festival in Toronto in September 2009 was the venue for the premiere of the British film, "Creation", the subtitle of which is "How Darwin Saw the World [and] Changed It Forever." The release of the film coincided with the $200^{\text {th }}$ anniversary of Charles Darwin's birth and the $15 \mathrm{O}^{\text {th }}$ anniversary of the publication of $\mathrm{On}$ the Origin of Species. The film is based on the book, Annie's Box: Charles Darwin, His Daughter, and Human Evolution, by Randal Keynes, a great-great grandson of Darwin. The focus of the book and the film is the importance to Darwin of the death of his ten-year old daughter, Annie, in I85I. As Janet Browne writes in her biography of Darwin: "This death was the formal beginning of Darwin's conscious dissociation from believing in the traditional figure of God. The doctrines of the Bible that [his wife] Emma took comfort in were hurdles he could not jump."' One of the scenes

\footnotetext{
${ }^{\mathrm{I}}$ Browne, Janet, (2003), Charles Darwin: Voyaging , London, Pimlico, 503.
} 
in the movie is an encounter between Darwin and a young orangutan in the London Zoo. Above the title "Creation" in the advertisement for the film is a picture of Darwin and the orangutan reaching out to one another, each with a finger almost touching the other's finger: an obvious reminder of the scene on the ceiling of the Sistine Chapel of God's creating Adam. Although the film is more of a melodrama than a didactic work, the title, "Creation", suggests a scientific alternative to religious belief. In fact, the book on which the film is based now appears with the new title, Creation: The True Story of Charles Darwin. ${ }^{2}$

Discussions about creation and evolution can easily become obscured in broader political, social, and philosophical contexts. Indeed, evolution and creation have taken on cultural connotations, serve as ideological markers, with the result that each has come to stand for a competing world-view.

For some, to embrace evolution is to affirm an exclusively secular and atheistic view of reality, and evolution is accordingly either welcomed or rejected on such grounds. In the Darwin film, for example, when a clergyman comes to visit a sick and despondent Charles Darwin, he seeks to reassure Darwin by telling him that "God moves in mysterious ways." To which Darwin replies: yes, "he has endowed us - in all his blessed generosity - with not one but 900 species of intestinal worm." On another occasion, the character who plays Thomas Huxley tells Darwin: "Sir, you have killed God."

Even if we resist the sense of polar opposites between creation and evolution, we might be attracted to the claim of the Catholic theologian, John Haught, that after the life and work of Charles Darwin "any thoughts we may have about God can hardly remain the same as before." As Haught observes, "Evolutionary science has changed our understanding of the world dramatically, and so any sense we may have of a God

${ }^{2}$ Keynes, Randal, (2009), Creation: The True Story of Charles Darwin, New York, Penguin Books. 
who creates and cares for this world must take into account what Darwin and his followers have told us about it."3

Process theologians and philosophers ask us to re-fashion our views of God and His relation to the world, such that they would appear more congenial in an evolutionary context. For them, God changes as the world changes and creation ex nihilo must be rejected since they think it violates a fundamental tenet of science: that it is impossible to get something from nothing. Although process thought has important scholarly proponents, the choice for many often seems to be between a purely natural explanation of the origin and development of life, an explanation in terms of common descent, genetic mutations, and natural selection as the mechanism of biological change, on the one hand, and, on the other hand, an explanation which sees divine agency as the source of life in all its diversity and that human beings, created in the image and likeness of God, have a special place in the universe. The difference appears stark: either Darwin or God.

What is at issue in current debates is not some naïve view that the Earth is only IO,OOO years old. Rather, for many believers, however old the world is, God is necessary to explain the order and design evident in it. At times this view has come to mean that God has directly intervened to create each of the different species of living things. It is precisely such an understanding of creation that many people think evolution denies. Not only does natural selection replace divine agency, but chance supplants order and design in explanations of the origin of life. ${ }^{4}$

${ }^{3}$ Haught, John, (2000), God After Darwin. A Theology of Evolution. Boulder, Colorado, Westview Press, ix.

${ }^{4}$ Jerry Coyne puts what he considers to be the core concern this way: "We resist the evolutionary lesson that, like other animals, we are contingent products of the blind and mindless process of natural selection. We just can't bring ourselves to acknowledge that, just like every other species, we too evolved from an ancestor that was very different." Coyne, Jerry A. (2009), Why Evolution is True, New York, Penguin, I92. "The lesson from the human fossil record, then, combined with more recent discoveries in human genetics, confirms that we are evolved mammals - proud and accomplished ones, to be sure, but mammals built by the same processes that transformed every form of life over the 
One of the more sophisticated attempts to draw theological implications from contemporary science is the work of Stuart Kauffman, famous for his studies in information systems and bio-complexity. He argues that we are "reinventing the sacred" as a result of a new view of science. This new view involves a rejection of reductionism and an affirmation of the emergent properties of a dynamic universe of "ceaseless creativity." As Kauffman observes, "life has emerged in the universe without requiring special intervention from a Creator God... All, I claim arose without a Creator God... Is not this view, a view based on an expanded science, God enough? Is not nature itself creativity enough? What more do we really need of God...?"5 Thus, to accept the dynamism in nature as an explanation of the changes and diversity in and among living things appears to do away with the need for a Creator. Such a view is also behind the fear which informs many believers who reject evolution in order to hold on to the need for a Creator: once again, either Darwin or God.

The sense of a fundamental incompatibility between creation and evolution is part of a wider intellectual framework in which scientific developments have been used to support a kind of "totalizing naturalism." This is the view that the universe and the processes within it need no explanation beyond the categories of the natural sciences. ${ }^{6}$ A particularly

past few billion years." 220. As Daniel Dennett remarks in Darwin's Dangerous Idea: "Science has won and religion has lost. Darwin's idea has banished the Book of Genesis to the limbo of quaint mythology." Or, as Christopher Hitchens in his popular book, God is Not Great, contends: "Religion has run out of justifications. Thanks to the telescope and the microscope, it no longer offers an explanation of anything important."

${ }^{5}$ Kauffman, Stuart, (2008), Reinventing the Sacred: A New View of Science, Reason, and Religion, New York, New York, Basic Books, 7I, 229, 283.

${ }^{6}$ "La nature est comprise comme auto-créatrice, ce terme connotant que la notion classique de création est devenue inutile. La Nature -- et il convient d'écrire le mot avec un majuscule -- est autosuffisante pour produire non seulement ses effets, mais pour se produire... La notion de création disparait dans cette perspective de la réflexion." Maldamé, Jean-Michel, (2006), Création et Providence: Bible, science et philosophie, Paris, Les Éditions du Cerf, I53. 
radical view of the implications for belief in God found in contemporary science, especially evolution, is that of Steven J. Dick, who speaks of a "natural God."

This idea of a supernatural God is, of course, a historical artifact, a product of the evolution of human thought... Although it has proven a resilient and flexible concept, a supernatural God is no different from other powerful ideas developed throughout history, in the sense that it is useful, persistent, and subject to change... A major effect of the concept of a natural God [that is, a God in the universe rather than outside it] is that it has the capacity to reconcile science and religion... A natural God is an intelligence in and of the world, a God amenable to scientific methods, or at least approachable by them. A supernatural God incorporates a concept all scientists reject in connection with their science... [T] he natural God of cosmic evolution and the biological universe, not the supernatural God of the ancient Near East, may be the God of the next millennium. ${ }^{7}$

Whether we speak of explanations of the Big Bang itself (such as quantum tunneling from nothing) or of some version of a multiverse hypothesis, or of self-organizing principles in biological change (including, at times, appeals to randomness and chance as ultimate explanations), the conclusion which seems inescapable to many is that there is no need to appeal to a creator, that is, to any cause which is outside the natural order. Here is how one cosmologist, Lee Smolin, has put it:

We humans are the species that makes things. So when we find something that appears to be beautifully and intricately

${ }^{7}$ Dick, Steven J. (2000), "Cosmotheology: Theological Implications of the New Universe", in Many Worlds. The New Universe, Extraterrestrial Life, and the Theological Implications, edited by Steven Dick, Philadelphia, Templeton Foundation Press, I9I-2IO, at 203, 204, and 208. Note the use of the phrase "of course" in the opening sentence of the quotation.

Tópicos 42 (2012) 
structured, our almost instinctive response is to ask, "Who made that?' The most important lesson to be learned if we are to prepare ourselves to approach the universe scientifically is that this is not the right question to ask. It is true that the universe is as beautiful as it is intrinsically structured. But it cannot have been made by anything that exists outside of it, for by definition the universe is all there is, and there can be nothing outside it. And, by definition, neither can there have been anything before the universe that caused it, for if anything existed it must have been part of the universe. So the first principle of cosmology must be 'There is nothing outside the universe...' The first principle means that we take the universe to be, by definition, a closed system. It means that the explanation for anything in the universe can involve only other things that also exist in the universe. ${ }^{8}$

But contrary to Smolin, as we shall see, to speak of God as Creator does not mean that $\mathrm{He}$ is either outside or before the universe, even though $\mathrm{He}$ is radically other than the universe of created things.

Many of those who are in opposing camps about the philosophical and theological implications of contemporary cosmology tend to share similar views concerning creation and the origin of the universe. That is, those who think cosmology shows us that there is a Creator understand what it means to be a Creator in essentially the same way as those who think that recent developments in cosmology eliminate the need for a Creator.

Indeed, the traditional reading of Genesis, confirmed by the solemn pronouncement of the Fourth Lateran Council (I2I 5), is that "in the beginning" means that the universe is temporally finite; the world and time began to be as the result of God's creative word. Historically, Big Bang cosmology which affirms a "singularity" or starting point for our uni-

${ }^{8}$ Smolin, Lee, (200I), Three Roads to Quantum Gravity, New York, Basic Books, 17 . 
verse - a point beyond the categories of space and time, and beyond the explanatory realm of physics - has been used to provide a kind of scientific confirmation for the traditional doctrine of creation. Even Pope Pius XII once remarked that this cosmology offered support for what the opening of Genesis revealed. ${ }^{9}$ If there were a Big Bang, so this argument affirms, then the universe began to be and thus there must be a Creator who caused the universe to begin to be. The relationship between the temporal finitude of the universe and the conclusion that it is created can be found in the recent work of the Jesuit theologian and cosmologist, Robert J. Spitzer. Spitzer thinks that modern physics reinforces the mediaeval Kalam cosmological argument and shows us that the past time of the universe is finite. ${ }^{\text {IO }}$

To speak of creation and the beginning of time as intimately connected - such that one necessarily entails the other - has often informed not only those who support creation but also those who use new theo-

9" [ $[\mathrm{t}$ would seem that present-day science, with one sweeping step back across millions of centuries, has succeeded in bearing witness to that primordial 'Fiat lux' uttered at the moment when, along with matter, there burst forth from nothing a sea of light and radiation... Thus, with that concreteness which is characteristic of physical proofs, it has confirmed the contingency of the universe and the well-founded deductions as to the epoch when the cosmos came forth from the hands of the Creator. Hence creation took place in time. Therefore, there is a Creator. Therefore, God exists!" Pope Pius XII, Address to the Pontifical Academy of Sciences, 22 November 195I.

${ }^{10}$ Spitzer, Robert J. (20I0), New Proofs for the Existence of God: Contributions of Contemporary Physics and Philosophy, Grand Rapids, Michigan, Eerdmans, especially chapter 5 (I77-2I5). Spitzer argues that developments in relativity theory and quantum mechanics have led to an ontological understanding of time quite different from that found in Aristotle and Thomas Aquinas (for whom time is viewed as the measure of motion). Combining what he terms these new conceptions of time with arguments about infinity informed by the German mathematician, David Hilbert (I862-I943), Spitzer thinks that he can show the impossibility of the "past infinity of time," thus proving that time must have a beginning, and hence must have a Creator. With respect to this topic, Spitzer notes the importance of William Lane Craig's, (1979), The Kalam Cosmological Argument, New York, Barnes and Noble.

Tópicos 42 (2012) 
ries in cosmology to deny creation. If creation necessarily means that the universe has a beginning, then an eternal universe, one without a temporal beginning, could not be a created universe. Thus, those who embrace new cosmological theories which propose an eternal series of "big bangs" (as, for example, the ever-repeating collisions of giant four-dimensional membranes) or a multiverse scenario according to which our universe is but one in an infinite number of universes, think they call into question the intelligibility of an absolute temporal beginning, and hence, so it is thought, they call into question the intelligibility of creation itself. Max Tegmark of the Massachusetts Institute of Technology offers perhaps the most radical version of the multiverse hypothesis when he proclaims that every universe that can possibly exist, actually does exist. As he says, "there are infinitely many other inhabited planets, including not just one but infinitely many copies of you - with the same appearances, name and memories. Indeed, there are infinitely many other regions the size of our observable universe, where every possible cosmic history is played out." I I

Many cosmologists who now routinely speak of what happened "before the Big Bang" think that to reject some original Big Bang is to eliminate the need for a Creator. They deny the need for a Creator because they think that "to be created" means to have a temporal beginning, which is fundamentally the same view of creation as that of those thinkers who use the idea of a primal Big Bang as evidence for a Creator. In such a scenario, accepting or rejecting a Creator is tied to accepting or to explaining away an original Big Bang. As we shall see, this is a fun-

II "The Multiverse Hierarchy", in Universe or Multiverse? edited by Carr, Bernard, (2007), Cambridge University Press, 99-I25, at IO2. According to Tegmark, the closest identical copy of each one of us is $\left(\mathrm{IO}^{\mathrm{IO}}\right)^{29}$ meters away: there is not much chance of running into that person. All of this occurs only at the most basic of four levels of multiverse scenarios. At level IV in this multiverse hierarchy, as Tegmark calls it, the physical world is only a mathematical structure and, as a result, he notes that the "properties of all parallel universes (including the subjective perceptions of every SAS [each one of us is a SAS, a "self-aware substructure"]) could in principle be derived by an infinitely intelligent mathematician.” I I8. 
damental error which each side shares. We can recall Stephen Hawking's famous rhetorical question in A Brief History of Time, (I988): "So long as the universe had a beginning, we could suppose it had a creator. But if the universe is really completely self-contained, having no boundary or edge, it would have neither beginning nor end: it would simply be. What place, then, for a creator?" No beginning, therefore no creator. In The Grand Design, ${ }^{\mathrm{I} 2}$ published in September 20IO, Hawking and his co-author, Leonard Mlodinow, make the same point. Just as the universe has no edge, so there is no boundary, no beginning to time. Therefore to ask what happened before the beginning - or even at the beginning - would be meaningless. "In the early universe - when the universe was small enough to be governed by both general relativity and quantum theory - there were effectively four dimensions of space and none of time. That means that when we speak of the 'beginning' of the universe, we are skirting the subtle issue that as we look backward toward the very early universe, time as we know it does not exist! We must accept that our usual ideas of space and time do not apply to the very early universe. That is beyond our experience, but not beyond our imagination." I3 Ultimately, they claim: "Spontaneous creation is the reason there is something rather than nothing, why the Universe exists, why we exist. It is not necessary to invoke God... to set the Universe going." "I4

Citing a version of contemporary string theory, known as " $\mathrm{M}$ theory", they tell us that the "creation" of a great many universes out of nothing "does not require the intervention of some supernatural being or god." Rather, these multiple universes "arise naturally from physical law." "5 Ultimate questions about the nature of existence which have intrigued philosophers for millennia are, so they claim, now the province of science, and "philosophy is dead." 16 Theology, if mentioned at all, is sim-

\footnotetext{
${ }^{\mathrm{I}}$ Hawking, Stephen and Mlodinow, Leonard, (2010), The Grand Design, New York, Bantam Books, 2010.

${ }^{13}$ Ibid., I34.

${ }^{\mathrm{I}}$ Ibid., I80.

${ }^{\text {I}}$ Ibid., 8-9.

${ }^{\mathrm{I}}$ Ibid., 5 .
} 
ply dismissed as irrelevant. ${ }^{\mathrm{I}}$ The new book has fewer than two hundred pages, divided into eight chapters, each with a suggestive title such as: "The Mystery of Being"; "What is Reality?"; "Choosing Our Universe"; "The Apparent Miracle"; and culminating in "The Grand Design." The principal argument they offer is that once we recognize that our universe is but one of an almost infinite number of universes then we do not need a special explanation - a Grand Designer - for the very precise initial conditions which account for life and our existence. As they say, “just as Darwin... explained how the apparently miraculous design of living forms could appear without intervention by a supreme being, the multiverse concept can explain the fine-tuning of physical law without the need for a benevolent creator who made the universe for our benefit."I8 But, the Grand Designer rejected by Hawking is not the Creator, at least not the Creator which traditional philosophy and theology affirms.

The alleged conflict between creation and science, based on developments in both evolutionary biology and cosmology, which often is found in rejections of science in defense of a Creator and in rejections of a Creator in defense of science is the result of confusions about what

${ }^{17}$ This was Hawking's answer to a query about theology in a television interview in the United States [The Larry King Show on CNN], Io September 2010.

${ }^{18}$ Hawking and Mlodinow, I65. "Bodies such as stars and black holes cannot just appear out of nothing. But a whole universe can. Because gravity shapes space and time, it allows space-time to be locally stable but globally unstable. On the scale of the entire universe, the positive energy of matter can be balanced by the negative gravitational energy, and so there is no restriction in the creation of whole universes. Because there is a law such as gravity, the universe can and will create itself from nothing." Hawking and Mlodinow, I80. "The ultimate theory must be consistent and must predict finite results for quantities that we can measure. We've seen that there must be a law such as gravity, and for a theory of gravity to predict finite quantities, the theory must have what is called supersymmetry between the forces of nature and the matter on which they act. M-theory is the most general supersymmetric theory of gravity. For these reasons M-theory is the only complete theory of the Universe. If it is finite - and this is yet to be proved - it will be a model of a Universe that creates itself." I80-I. 
creation is and what the explanatory extent of the natural sciences is. Creation, as a metaphysical and theological notion, affirms that all that is, in whatever way or ways it is, depends upon God as cause. The natural sciences have as their subject the world of changing things: from subatomic particles to acorns to galaxies. Whenever there is a change there must be something that changes. Whether these changes are biological or cosmological, without beginning or end, or temporally finite, they remain processes. Creation, on the other hand, is the radical causing of the whole existence of whatever exists. Creation is not a change. To cause completely something to exist is not to produce a change in something, is not to work on or with some existing material. When God's creative act is said to be "out of nothing," what is meant is that God does not use anything in creating all that is: it does not mean that there is a change from "nothing" to "something."

Evolutionary biology, cosmology, and all the other natural sciences offer accounts of change; they do not address the metaphysical and theological questions of creation; they do not speak to why there is something rather than nothing. It is a mistake to use arguments in the natural sciences to deny creation. But, as we shall see, it is also a mistake to appeal to cosmology as a confirmation of creation. Reason (as well as faith) can lead to knowledge of the Creator, but the path is in metaphysics not in the natural sciences. Discussions of creation are different from arguments from order and design to a source of order and design. Natural philosophy may help us to recognize that there is an Unmoved Mover or an ultimate source of the fine-tuning of the initial conditions of the universe, but metaphysics is necessary to reach the conclusion that there is a Creator, the source of existence. To offer explanations of fine-tuning without an appeal to a Grand Designer, as Hawking and Mlodinow do, tells nothing about creation and a Creator.

To avoid confusion, we need to remember the different senses of how we use the term "to create." We often speak of human creations, especially with respect to the production of works of art, music, and literature. What it means for God to create is radically different from any kind of human making. When human beings make things they work with 
already existing material to produce something new. The human act of creating is not the complete cause of what is produced; but God's creative act is the complete cause of what is produced; this sense of being the complete cause is captured in the expression "out of nothing." To be such a complete cause of all that is requires an infinite power, and no creature, no human being, possesses such infinite power. God wills things to be and thus they are. To say that God is the complete cause of all that is does not negate the role of other causes which are part of the created natural order. Creatures, both animate and inanimate, are real causes of the wide array of changes that occur in the world, but God alone is the universal cause of being as such. God's causality is so different from the causality of creatures that there is no competition between the two; that is, we do not need to limit, as it were, God's causality to make room for the causality of creatures. God causes creatures to be causes. ${ }^{19}$ For example, He causes biological and cosmological processes to be what they are.

Already in the $13^{\text {th }}$ Century the groundwork was set for the fundamental understanding of creation and its relationship to the natural sciences. Working within the context of Aristotelian science and aided by the insights of Muslim and Jewish thinkers, as well as his Christian predecessors, Thomas Aquinas provided an understanding of creation and science which remains true. The distinction between creation and change - and hence between the explanatory realm of the natural sciences and creation - to which I have already referred, is a key feature of 'Thomas' analysis. As he wrote: "Over and above the mode of becoming by which something comes to be through change or motion, there must be a mode of becoming or origin of things without any mutation or motion, through the influx of being." 20

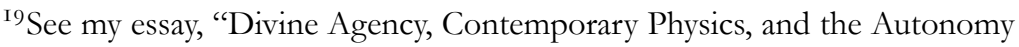
of Nature," The Heythrop Journal 49:4 (July 2008), 582-602.

20"Oportet igitur supra modum fiendi quo aliquid fit per mutationem vel motum, esse aliquem modum fiendi sive originis rerum absque omni mutatione vel motu per influentiam essendi." Thomas Aquinas, On Separated Substances, c.9.
} 
Creation is not primarily some distant event; rather, it is the on-going complete causing of the existence of all that is. At this very moment, were God not causing all that is to exist, there would be nothing at all. Creation concerns first of all the origin of the universe, not its temporal beginning. Indeed, it is important to recognize this distinction between origin and beginning. The former affirms the complete, continuing dependence of all that is on God as cause. It may very well be that the universe had a temporal beginning, but there is no contradiction in the notion of an eternal, created universe: for were the universe to be without a beginning it still would have an origin, it still would be created. This was precisely the position of Thomas Aquinas, who accepted as a matter of faith that the universe had a temporal beginning but also defended the intelligibility of a universe, created and eternal. To predicate eternity of the universe is very different from referring to God as eternal. The former refers to temporal succession without beginning or end; in God there is no temporal succession at all.

Thomas thought that neither science nor philosophy could know whether the universe had a beginning. He did think that metaphysics could show us that the universe is created, ${ }^{2 \mathrm{I}}$ but he would have warned against those today who use Big Bang cosmology, for example, to conclude that the universe has a beginning and therefore must be created. He was always alert to reject the use of bad arguments in support of what is believed. The "singularity" in traditional Big Bang cosmology may represent the beginning of the universe we observe, but we cannot conclude that it is the absolute beginning, the kind of beginning which would indicate creation. Projected experiments to be performed at the Large Hadron Collider - the huge underground particle accelerator on

${ }^{2 \mathrm{I}}$ The argument involves a recognition that the difference between what things are (their essences) and that they are (their existence) must ultimately be resolved in a reality (God) in whom essence and existence are identical. Thus, what it means to be God is to be, and God is the uncaused cause of all beings. One need not accept the validity of Thomas' claim to demonstrate that the universe is created in order to understand his distinction between creation and science and that "to create" is not to produce a change.

Tópicos 42 (20I2) 
the Swiss-French border - may bring us closer to what happened just after the Big Bang; but they will tell us nothing about creation. The distance between minute fractions of a second after the Big Bang and creation is, in a sense, infinite. We do not get closer to creation by getting closer to the Big Bang. Furthermore, as some contemporary cosmologists recognize, there could very well be something before the Big Bang.

Some cosmologists have used insights from quantum mechanics to offer accounts of the Big Bang itself. They speak of the Big Bang in terms of "quantum tunnelling from nothing," analogous to the way in which very small particles seem to emerge spontaneously from vacuums in laboratory experiments. Thus, they think that to explain the Big Bang in this way, as the fluctuation of a primal vacuum, eliminates the need to have a Creator. But the Big Bang "explained" in this way is still a change and, as we have seen, creation, properly understood is not a change at all. Similarly, the "nothing" in these cosmological models which speak of "quantum tunnelling from nothing" is not the nothing referred to in the traditional sense of creation out of nothing. The "nothing" in cosmological reflections may very well be nothing like our present universe, but it is not the absolute nothing central to what it means to create; it is only that about which the theories say nothing. The crucial point here is that to offer a scientific account of the Big Bang is not to say anything about whether or not the universe is created.

Those contemporary cosmological theories which employ a multiverse hypothesis or an infinite series of big bangs do not challenge the fundamental feature of what it means to be created, that is, the complete dependence upon God as cause of existence. An eternal universe would be no less dependent upon God than a universe which has a beginning of time. For one who believes that the universe has a temporal beginning, any theory of an eternal universe would have to be rejected, but a believer should be able to distinguish between the question of the kind of universe God creates (e.g., one with a temporal beginning) and the fact that whatever kind of universe there is, God is its Creator. To reiterate: science cannot tell us for sure whether the universe has an absolute temporal beginning or whether it is eternal. In such a scenario it is only by 
faith that one can conclude that there is a beginning. Since reason alone remains silent about an absolute beginning, what faith affirms does not challenge what reason can legitimately claim to be true. Cosmology does offer speculations which deny a beginning, but these speculations do not really deny the fundamental sense of what it means to be created - that is, to depend upon God for existence (even eternal existence).

When it came to how to read the opening of Genesis, Thomas Aquinas observed that what is essential is the "fact of creation," not the "manner or mode" of the formation of the world. In his Scriptum on the 'Sentences' of Peter Lombard, Thomas sketches the debate between two traditions, one favored by Albert the Great, the other by Bonaventure on: "whether all things were created simultaneously and as distinct species." In his reply, he observes:

There are some things that are by their very nature the substance of faith (substantia fidei), as to say of God that He is three and one, and other similar things, about which it is forbidden for anyone to think otherwise... There are other things that relate to the faith only incidentally... and, with respect to these, Christian authors have different opinions, interpreting the Sacred Scripture in various ways. Thus with respect to the origin of the world (circa mundi principium), there is one point that is of the substance of faith, viz., to know that it began by creation (mundum incepisse creatum), on which all authors in question are in agreement. But the manner and the order according to which creation took place concerns the faith only incidentally (non pertinet ad fidem nisi per accidens), in so far as it has been recorded in Scripture, and of these things aforementioned authors, safeguarding the truth by their various interpretations, have reported different things. ${ }^{22}$

Questions concerning order, design, and chance in nature refer to the "manner or mode" of formation of the world. Attempts in the natural

${ }^{22}$ In II Sent., dist. I2, q. I, a. 2.

Tópicos 42 (2012) 
sciences to explain these facets of nature do not challenge the "fact of creation." Natural selection is not an alternative to divine agency. Chance mutations do not call into question God as Creator. God causes things both to be the kinds of things which they are and to exercise the kind of causality which is properly their own. Even the reality of chance and contingency depends upon God as cause. God transcends the created order in such a radical way that $\mathrm{He}$ is able to be active in the world without being a competing cause in the world. So, one does not have to choose between evolutionary biology and creation; to affirm one need not be a denial of the other; we can have both Darwin and God.

Addressing the Pontifical Academy of Sciences in October 2008, Pope Benedict XVI distinguished between limiting creation to the beginning of things and seeing it as the continuing source of the existence of things:

To state that the foundation of the cosmos and its developments is the provident wisdom of the Creator is not to say that creation has only to do with the beginning of the history of the world and of life. It implies, rather, that the Creator founds these developments and supports them, underpins them and sustains them continuously. Thomas Aquinas taught that the notion of creation must transcend the horizontal origin of the unfolding of events, which is history, and consequently all our purely naturalistic ways of thinking and speaking about the evolution of the world. Thomas observed that creation is neither a movement nor a mutation. It is instead the foundational and continuing relationship that links the creature to the Creator, for he is the cause of every being and all becoming. ${ }^{23}$

The interconnected world of changing things, what the Pope calls the horizontal realm of unfolding events, ought not to be confused with the

${ }^{23}$ Pope Benedict XVI, Address to the Plenary Meeting of the Pontifical Academy of Sciences (3I October 2008). 
vertical dimension of creation: a vertical dimension upon which the horizontal continues to depend for its very existence. Order, design, chance, and contingency all concern the horizontal realm; the very reality of all things depends upon the vertical dimension. We ought not to think that to create, in its primary sense, means to produce order - or to be the ultimate 'fine tuner' of the universe's initial conditions. To explain order and design in terms of processes within nature does not eliminate the need for a Creator, a Creator who is responsible for the existence of nature and everything in it. We do not need to follow the advice of process theologians and adjust our understanding of God - to deny his omnipotence and to have him changing as the world changes - in order to accommodate an evolutionary view of the world. The traditional understanding of God as Creator, set forth, for example, by Thomas Aquinas, needs no such tinkering.

God's creative power is exercised throughout the entire course of cosmic history, in whatever ways that history has unfolded. God creates a universe in which things have their own causal agency, their own true self-sufficiency: a nature which is susceptible to scientific analysis. Still, no explanation of cosmological or biological change, no matter how radically random or contingent such an explanation claims to be, challenges the metaphysical account of creation, that is, of the dependence of the existence of all things upon God as cause. When some thinkers deny creation on the basis of theories in the natural sciences, or reject the conclusions of these sciences in defense of creation, they misunderstand creation or the natural sciences, or both. 